\title{
Effects of Combination Treatment in Hypertensive Patients with Depression: A Systematic Review and Meta-Analysis of 27 Randomized Controlled Trials
}

\author{
Lin Wang $\mathbb{D}^{\prime}$, Qingqing Liu², Dongsheng Sun', Jianhong Xie', Dibo Lao', Li Zhang' \\ 'Heart Center, Department of Geriatrics, Zhejiang Provincial People's Hospital (Affiliated People's Hospital, Hangzhou Medical College), Hangzhou, \\ Zhejiang, 3100 I4, People's Republic of China; ${ }^{2}$ Department of Respiratory and Critical Care Medicine, Shulan (Hangzhou) Hospital, Hangzhou, \\ Zhejiang, People's Republic of China
}

Correspondence: Li Zhang, Heart Center, Department of Geriatrics, Zhejiang Provincial People's Hospital (Affiliated People's Hospital, Hangzhou Medical College), No. 158 Shangtang Road, Hangzhou, 310014, Zhejiang, People's Republic of China, Tel/Fax +86 57I-85893957,

Email blueapplez|@।63.com

\begin{abstract}
Background: Hypertension commonly co-exists with depression and is associated with adverse health outcomes. This meta-analysis aimed to examine whether combination treatment can improve the outcomes of patients with comorbid hypertension and depression. Methods: We searched for relevant randomized controlled trials (RCTs) published through July 2021 using PubMed, Web of Science, China National Knowledge Infrastructure, and Wanfang Data. RCTs on patients with an antihypertensive outcome and data on mean blood pressure differences were extracted for both intervention and control groups. Continuous and dichotomous measures of outcomes were pooled using weighted mean differences (WMD) and risk ratios (RR) with 95\% confidence intervals (CI) by random or fixed effects. Subgroup and meta-regression analyses were performed to identify any existing heterogeneous sources.

Results: A total of 27 RCTs with 2606 participants were included. Combination treatment significantly improved systolic blood pressure (SBP) by $11.27 \mathrm{mmHg}\left(\mathrm{WMD}=-11.27,95 \% \mathrm{CI}:-14.12\right.$ to -8.43 ), $\mathrm{I}^{2}=95.4 \%$ ), diastolic blood pressure (DBP) by 8.21 $\mathrm{mmHg}$ (WMD $=-8.21,95 \% \mathrm{CI}:-10.73$ to -5.69$), \mathrm{I}^{2}=96.9 \%$ ), and antihypertensive efficiency by $42 \%$ (RR $=1.42,95 \% \mathrm{CI}: 1.32$ to $1.52, \mathrm{I}^{2}=0.0 \%$ ) compared with in the control group. Combination treatment improved SBP and DBP levels in patients aged $<65$ years compared with those in patients aged $\geq 65$ years ( $\mathrm{p}=0.020$ and 0.007 , respectively).

Conclusion: Pooled evidence suggests that combination treatment significantly improves both blood pressure levels and antihypertensive efficiency in hypertensive patients with depression. Elderly patients with comorbid hypertension and depression may require a more collaborative approach to improve their outcome.
\end{abstract}

Registration: PROSPERO registration number CRD42020213430. Registered on November 08, 2020.

Keywords: hypertension, depression, combination treatment, meta-analysis, RCTs

\section{Introduction}

Hypertension is one of the major worldwide causes of cardiovascular disease (CVD) and premature death. ${ }^{1-3}$ Global estimates suggest that one-third of adults (1.39 billion) had hypertension in $2010{ }^{4}$ Previously, it was estimated that lowering systolic (SBP) and diastolic blood pressure (DBP) in the US population by 5.0 and $3.0 \mathrm{mmHg}$, respectively, can reduce the incidence of coronary artery disease by $15 \%$ and stroke by $27 \%$, whereas an increase in SBP by $20 \mathrm{mmHg}$ and DBP by $10 \mathrm{mmHg}$ in adults doubles the risk of developing CVD. ${ }^{5}$

Hypertension commonly co-exists with depression. ${ }^{6}$ Depression affects approximately one-third of patients with hypertension. ${ }^{7}$ Co-existence of the two conditions complicates treatment; for instance, depression may affect medication adherence in patients with hypertension. ${ }^{8,9}$ In addition, depression can trigger dysfunction of the autonomic nervous system and hypothalamic-pituitary-adrenal axis, increasing vascular tone and resistance and affecting blood pressure. ${ }^{10}$ 
Conversely, uncontrolled hypertension aggravates symptoms of depression. Therefore, evidence suggests a bidirectional relationship between depression and hypertension. ${ }^{11}$

Although depression combined with hypertension could have additional adverse impacts on physical function and quality of life, there are still insufficient data to prove that combination treatment (antihypertensive and antidepressant treatment) in hypertensive patients with depression can improve their conditions. Several randomized controlled trials (RCTs) have indicated that, compared with usual antihypertensive treatment, combination treatment significantly improves control of both hypertension and depression. ${ }^{12,13}$ However, the sample sizes of these studies were rather small. Furthermore, some studies reported that the use of antidepressants improves only the symptoms of depression, but does not affect blood pressure. ${ }^{14}$ Moreover, there are studies reporting that the use of antidepressants increases blood pressure. ${ }^{15}$ Since the evidence is inconsistent, we are still unsure whether combination treatment, as a truly integrated intervention, improves both hypertension and depression outcomes.

Therefore, the primary aim of this systematic review and meta-analysis was to examine whether combination treatment would improve hypertension outcomes in patients with both hypertension and depression. The secondary aim was to explore whether it would improve depression outcomes.

\section{Methods}

\section{Search Strategy}

Our systematic review and meta-analysis were designed, conducted, and reported according to the Preferred Reporting Items for Systematic Reviews and Meta-Analyses (PRISMA) standards (Supplementary Table 1), and the study protocol was registered with PROSPERO (CRD42020213430). Relevant RCTs for the effect of combination treatment on blood pressure published through July 31, 2021, were systematically searched using several electronic databases, including PubMed, Web of Science, China National Knowledge Infrastructure (CNKI), and Wanfang. A comprehensive search strategy was used, further detailed in Supplementary Table 2: ("depression" OR "depressive disorder" OR "dysthymic disorder") and ("hypertension" OR "hypertensive patients" OR "high blood pressure" OR "blood pressure") and ("clinical trial" OR "randomized trial" OR "randomized controlled trial" OR "clinical" OR "randomized"). The search language was English and Chinese.

\section{Study Selection}

We included RCTs that satisfied all of the following criteria: (1) a diagnosis of both depression and hypertension; (2) trials with both female and male patients of any age; (3) a minimum intervention duration of 4 weeks; (4) a diagnosis of depression according to one of the following: a) assessment through clinician-rated and/or structured psychiatric interview and/or self-rated validated instruments, such as Self-Rating Depression Scales (SDS); b) diagnosis made by physicians according to the International Classification of Diseases, or a current prescription for antidepressant medication; (5) diagnosis of hypertension according to one of the following: a) a diagnosis made by physicians and/or current prescription for anti-hypertension medication; b) participants with self-reported hypertension; (6) study design: RCTs; (7) intervention: combination treatment: commonly used antihypertensive treatment and antidepressant treatment; and (8) comparison: the same common antihypertensive treatment as the intervention group.

\section{Outcomes}

The primary outcomes included one of the following: a) the mean difference in SBP and DBP between intervention and control groups; b) antihypertensive efficiency rate: markedly efficient cases were defined as those where DBP levels reached a normal range after decreasing by $\geq 10 \mathrm{mmHg}$ or DBP levels that decreased by $>20 \mathrm{mmHg}$; efficient cases were defined as those whose DBP levels reached a normal range after decreasing by $<10 \mathrm{mmHg}$ or DBP levels that decreased from 10 to $19 \mathrm{mmHg}$. Failed to meet the listed criteria was considered invalid. Total efficiency rate $=$ (markedly efficient cases + efficient cases)/total number of cases. The secondary outcome was depression remission. 


\section{Data Extraction and Quality Assessment}

The title or abstracts of eligible RCTs were evaluated by two authors (L. W. and D. S.) based on inclusion criteria. When discrepancies arose, a third author (L. Z.) was invited to be the deciding vote in the final discussion. For each included trial, two authors independently extracted the primary data and assessed their quality using a standardized data collection form. The following information was collected from each eligible trail: first author's name, country, publication year, participant demographics (age range, mean age, and sex ratio), treatment duration, sample size (intervention/control groups), type of antidepressant drugs, type of antihypertensive drugs, and primary and secondary outcomes before and after intervention. If important information was unavailable, we contacted the corresponding or first author by email a maximum of two times within a 1-month time period to obtain further details.

We assessed the risk of bias for the included studies using the Cochrane Risk of Bias Assessment Tool in seven different categories. ${ }^{16}$ Two authors (J.X and D.L) conducted the quality assessment independently. Any disagreements were resolved by the third author (Q.L).

\section{Statistical Methods}

The mean and standard deviation of SBP and DBP were extracted for both intervention and control groups from the eligible studies. The weighted mean differences (WMDs) and its 95\% confidence intervals (CIs) between the intervention and control groups were calculated for SBP and DBP. Between-study heterogeneity was examined using the Cochran $\mathrm{Q}$ test and $\mathrm{I}^{2}$ statistic. ${ }^{17,18}$ If pooled data showed an $\mathrm{I}^{2}$ of $>50 \%$, indicating significant heterogeneity, a random-effect model was used; otherwise, a fixed-effects model was used. ${ }^{17}$ Subgroup analysis and meta-regression were performed to identify possible sources of heterogeneity based on pre-specified characteristics, including country (China, United States), mean age ( $<65$ years, $\geq 65$ years), assessment of depression (Hamilton Depression Scale (HAMD), others), type of antidepressant drugs (tricyclic antidepressants (TCA), selective serotonin reuptake inhibitor (SSRI)), year of publication (Before 2010, After 2010) and sample size $(<100, \geq 100)$.

The outcome of antihypertensive efficiency was dichotomous variable. Relative risks (RRs) with $95 \%$ CIs for the effects of combination treatment on antihypertensive efficiency were calculated. We further examined the effects of combination treatment on depression scores and pooled standardized mean difference (SMD) from each RCT and associated 95\% CIs to produce an overall efficiency estimate for both intervention and control groups. We performed meta-regression analysis to test the hypothesis that SMD in depression score is a predictor of WMD in SBP and DBP levels.

We also performed sensitivity analysis (ie, recalculating the pooled estimate by omitting one study) to assess the robustness of meta-regression results with significant heterogeneity. Publication bias was examined using the Begg rank correlation test ${ }^{19}$ and Egger linear regression test, ${ }^{20}$ with significance set at a p-value of $<0.10$. All analyses were performed in Stata V14.0 (StataCorp, College Station, TX, USA) using "metan", "metareg", 'metabias', and "metaninf" commands. The effects were considered statistically significant when the associated $95 \%$ CI did not include zero for WMD and SMD, or one for RR.

\section{Results}

\section{Literature Search}

Figure 1 illustrates a flow chart summarizing the results of the potentially relevant literature search and trial selection process. Overall, 1709 records were identified after duplicates were removed. After screening and assessing the titles and/ or abstracts based on the inclusion criteria, 1663 studies were excluded and the remaining 46 studies underwent a second full-text review and screening. Finally, 19 additional studies were excluded for the reasons listed in Figure 1, with a total of 27 RCTs for final inclusion in the qualitative and quantitative analyses.

\section{Studies Characteristics}

Supplementary Table 3 summarizes the detailed characteristics of the included RCTs. The 27 trials, included a total of 2606 participants with both hypertension and depression who were receiving combination treatment for both conditions. Three of the included trials were conducted in the United States, and the others were conducted in China. ${ }^{12-14,21-44}$ All 


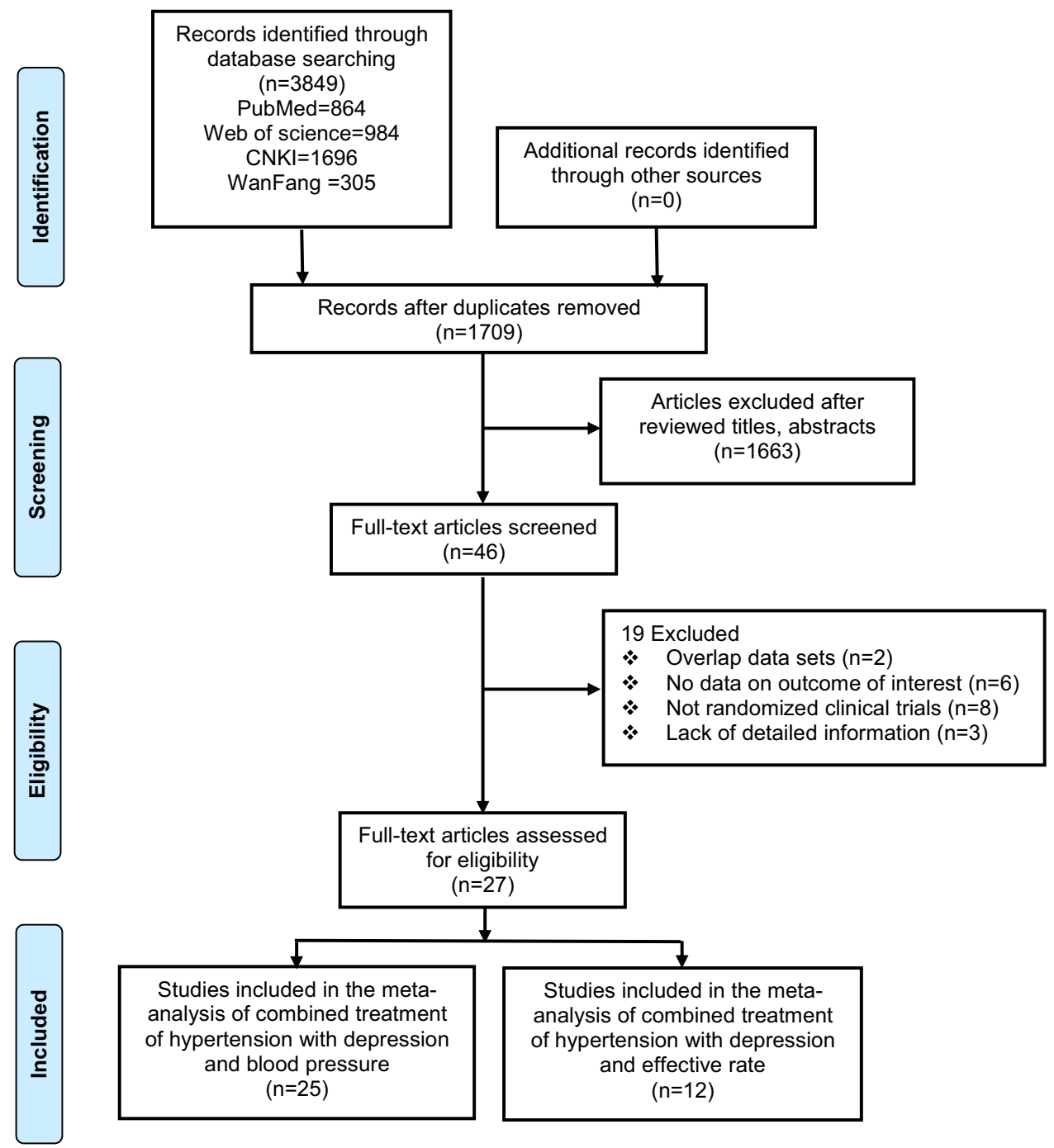

Figure I Preferred Reporting Items for Systematic Reviews and Meta-Analyses (PRISMA) flow chart. Adapted from Liberati A. Altman DG, Tetzlaff J, et al. The PRISMA statement for reporting systematic reviews and meta-analyses of studies that evaluate health care interventions: explanation and elaboration. PLoS Medicine. 2009;6(7): el000100. doi:10.137I/journal.pmed.1000100. () 2009 Liberati et al. Creative Commons Attribution License. ${ }^{54}$

trials included both female and male participants. The baseline ages of the participants ranged from 48 to 77 years. Twenty-four studies reported detailed names of antidepressants used in the intervention group. ${ }^{13,14,23-44}$ The duration of interventions ranged from 4 to 12 weeks. The primary outcomes were SBP and DBP changes in 25 studies with a total of 2435 patients, ${ }^{12-14,21-25,27,29,30,32-44}$ and effectiveness of anti-hypertensive treatment in twelve studies with a total of 1235 patients. $^{13,14,23,24,26-29,31,35,40,44}$ The results of the Cochrane quality assessment for the included studies are presented in Supplementary Figures 1 and $\underline{2}$.

\section{Quantitative Data Synthesis}

\section{Effects of Combination Treatment on Blood Pressure}

Figure 2 shows the WMD of SBP outcomes after treatment in the intervention and control groups. Combination treatment significantly improved WMD in SBP by $11.27 \mathrm{mmHg}$ compared with common antihypertensive treatment (pooled WMD, $-11.27 ; 95 \%$ CI: -14.12 to -8.43$)$. There was significant heterogeneity across these studies $\left(\mathrm{I}^{2}=95.4 \%\right.$, $\mathrm{p}<0.001)$, mostly due to variations in the degree of improvement. Combination treatment was favored in all but two studies. 


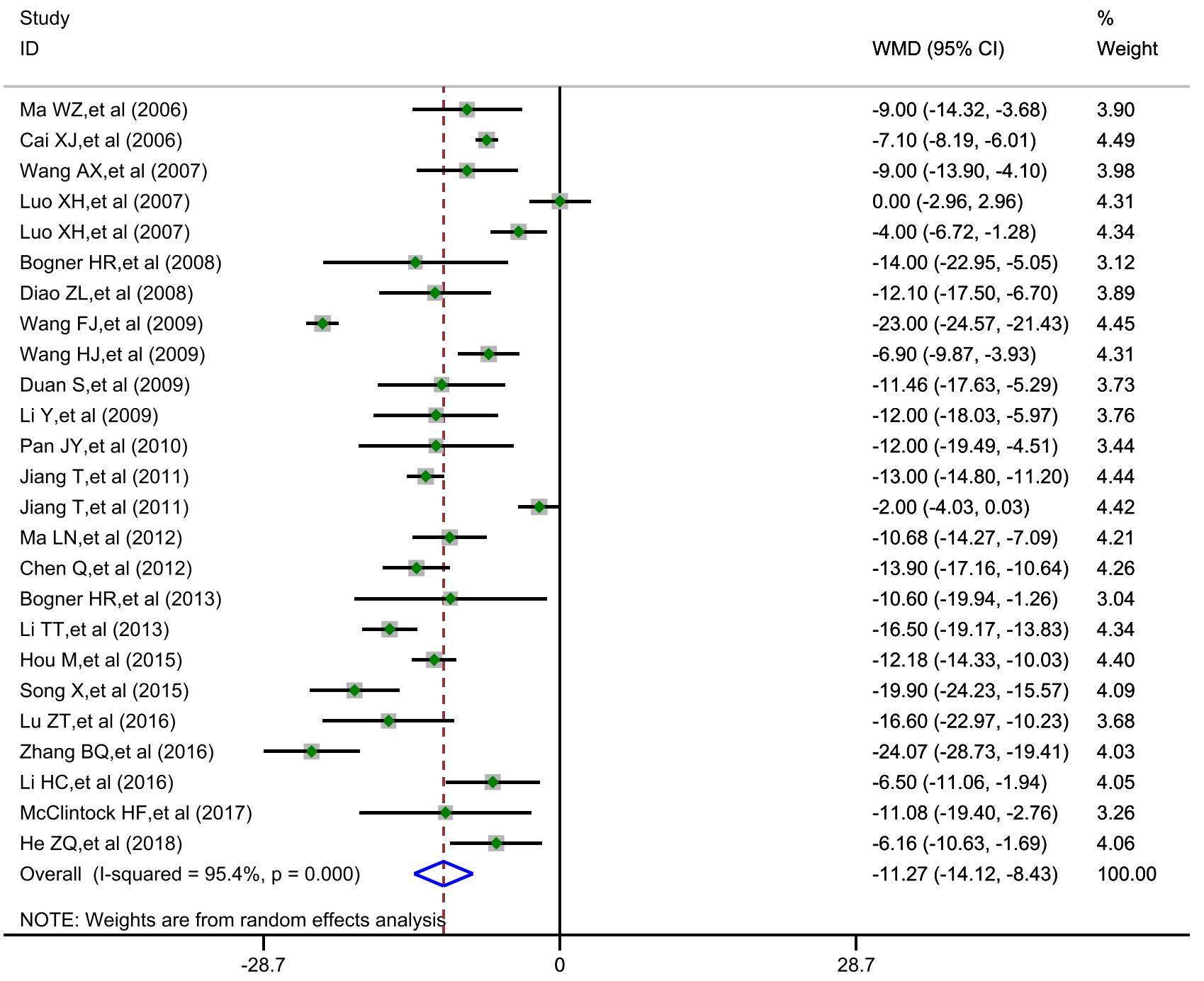

Figure 2 SBP values were estimated from meta-analysis of hypertensive depression patients with combination treatment (intervention group) versus usual antihypertensive treatment (control group).

The effect of the combination treatment on WMD in DBP outcomes is presented in Figure 3. Pooled effect sizes from random-effect models revealed that combination treatment significantly improved WMD in DBP by $8.21 \mathrm{mmHg}$ compared with in the control groups (pooled WMD, -8.21 ; $95 \%$ CI: -10.73 to -5.69 ). Significant heterogeneity was observed among the studies $\left(\mathrm{I}^{2}=96.9 \%, \mathrm{p}<0.001\right)$.

\section{Effects of Combination Treatment on Improvement in Hypertension}

Twelve trials provided information on total cases with antihypertensive outcomes used to calculate the overall effect size. The pooled analysis revealed that combination treatment was associated with a significant increase in antihypertensive effects at the end of follow-up $\left(R R=1.42,95 \% C I=1.32-1.52 ; p=0.452\right.$ for heterogeneity; $\left.I^{2}=0.0 \%\right)$ (Figure 4). An RR of 1.42 indicated a $42 \%$ relative increase in antihypertensive effects when combination treatment is used. No significant heterogeneity was observed among the studies.

\section{Effects of Combination Treatment on Depression Score}

Pooled effect sizes obtained using random-effect models revealed that combination treatment significantly improved standardized depression outcomes compared with in the control group (pooled SMD, $-2.19 ; 95 \% \mathrm{CI},-2.72$ to -1.66 ) (in Figure 5). There was significant heterogeneity across the studies $\left(\mathrm{I}^{2}=95.5 \%, \mathrm{p}<0.001\right)$. 


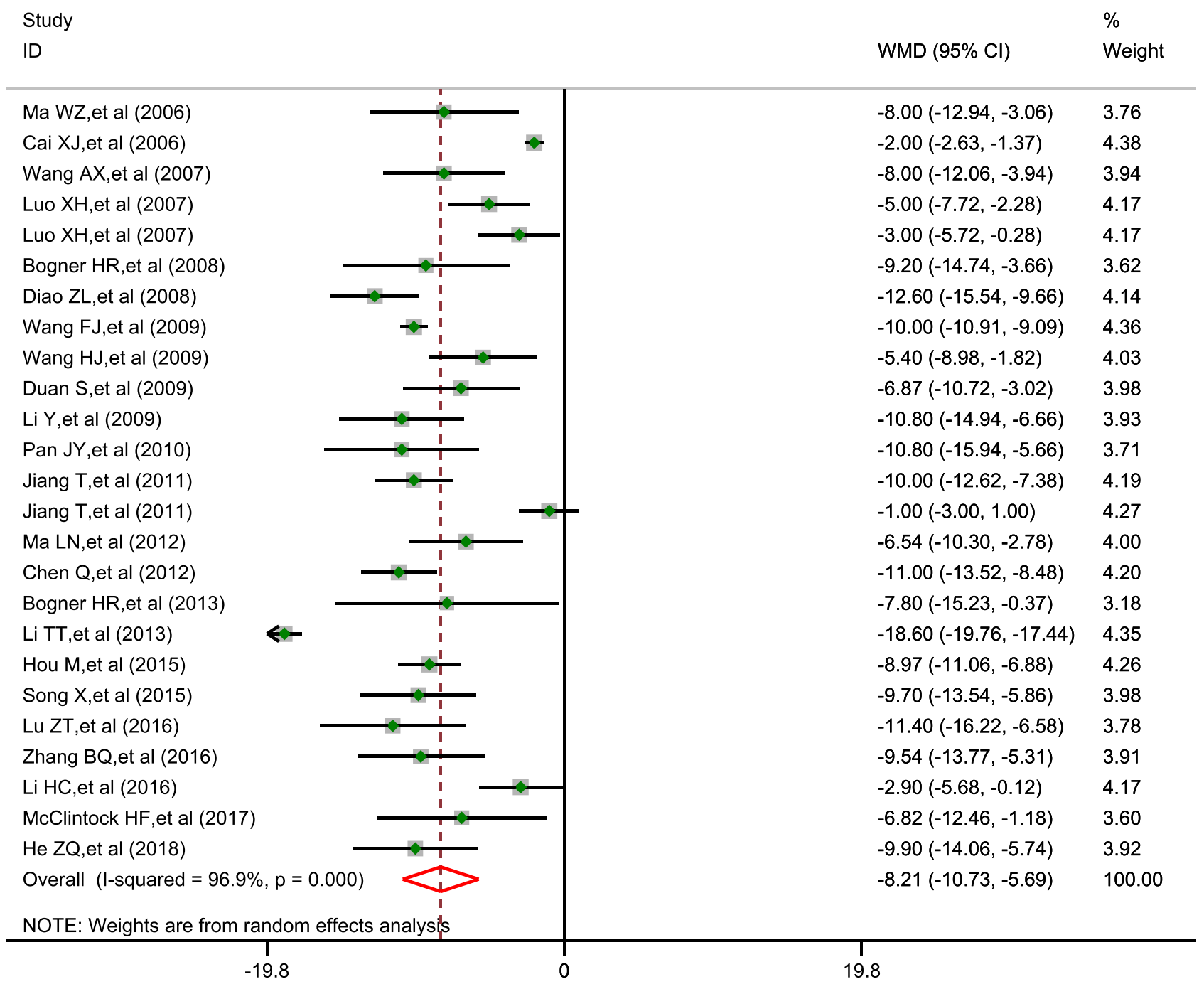

Figure 3 DBP values were estimated from meta-analysis of hypertensive depression patients with combination treatment (intervention group) versus usual antihypertensive treatment (control group).

\section{Effects of Depression Remission on SBP and DBP}

Scatter plots based on each study showed the relationship of SMD in depression score to the WMD in SBP and DBP values (Figure 6A and B). Meta-regression analysis indicated that the SMD for depression scores was not associated with $\mathrm{WMD}$ in SBP and DBP values across studies [coefficient $=0.529(95 \% \mathrm{CI}:-1.872$ to 2.930$), \mathrm{p}=0.644$, and coefficient $=$ 0.645 (95\% CI: -0.984 to 2.275$), \mathrm{p}=0.410$, respectively].

\section{Subgroup Analyses}

To examine the stability of primary results, we conducted subgroup analyses stratified by country, mean age, depression assessment methods, types of antidepressant drugs, publication years and sample sizes, and similar and consistent results were observed for the effects of combination treatment on SBP and DBP (Tables 1 and 2). However, WMD in SBP and DBP decrease after combination treatment was greater for patients aged $<65$ years than for patients aged $\geq 65$ years ( $\mathrm{p}$-value for difference $=0.020$ in SBP, $\mathrm{p}$-value for difference $=0.007$ in DBP).

\section{Meta-Regression Analysis}

Multivariable meta-regression analyses were performed to explore the sources of heterogeneity. The analyses showed that age, depression assessment methods, and study publication years were significantly correlated with heterogeneity in 
Study

ID
$\%$

RR $(95 \% \mathrm{Cl}) \quad$ Weight

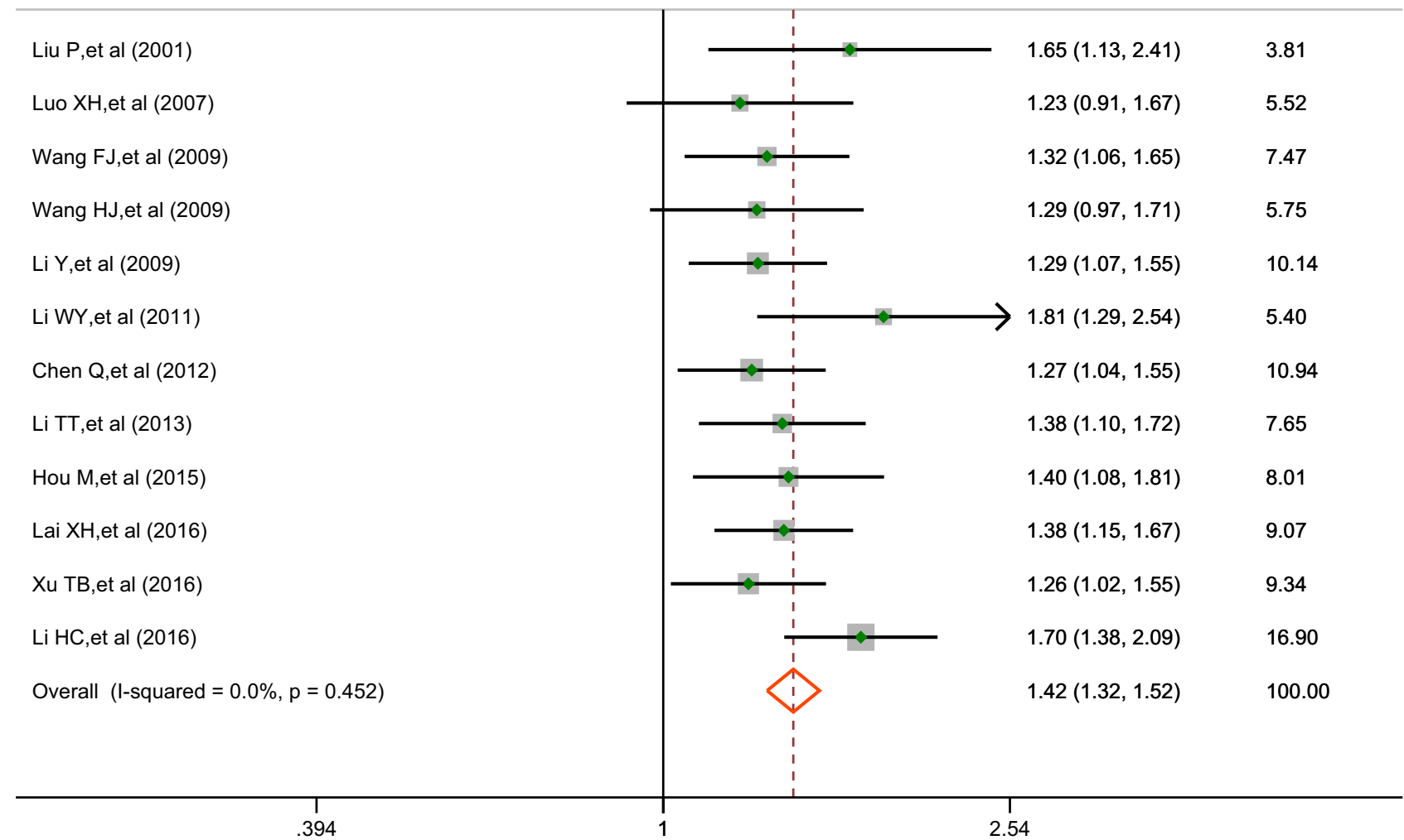

Figure 4 Efficiency of antihypertensive treatment were estimated from meta-analysis of hypertensive depression patients with combination treatment (intervention group) versus usual antihypertensive treatment (control group).

the effects of combination treatment on SBP $(p=0.015, p=0.024$, and $p=0.013$, respectively) (Table 3). Age and study publication year were found to be significantly associated with heterogeneity in the effects of combination treatment on DBP ( $p=0.003$ and $p=0.037$, respectively) (Table 4). Univariate meta-regression showed that age was the main source of heterogeneity, calculated at $21.2 \%$ and $29.7 \%$ of the variance across studies for SBP and DBP outcomes, respectively.

\section{Sensitivity Analysis}

There were significant heterogeneity across studies when we pooled the WMD of SBP and DBP between intervention and control groups. Sensitivity analyses were conducted for the pooled WMD in SBP and DBP $\left(I^{2}>50 \%\right)$. The results of the sensitivity analysis revealed that after recalculating the pooled WMD when one study was excluded, WMD in SBP and DBP remained statistically significance $(\mathrm{p}<0.05)$ between the intervention and control groups (Figures 7 and 8 ), indicating the robustness and stability of the results.

\section{Publication Bias}

A systematic assessment of bias in the included studies was presented in Supplementary Table 4. The Begg and Egger tests for the effects of combination treatment on SBP, DBP, and the antihypertensive efficiency suggested that there was no significant publication bias ( $\mathrm{P}>0.05$ ) (Supplementary Figures 3-5).

\section{Discussion}

The results of this meta-analysis, performed on 27 RCTs including a total of 2606 hypertensive patients with depression, revealed a higher efficiency of combination treatment on SBP and DBP decrease as well as a greater antihypertensive effect, 


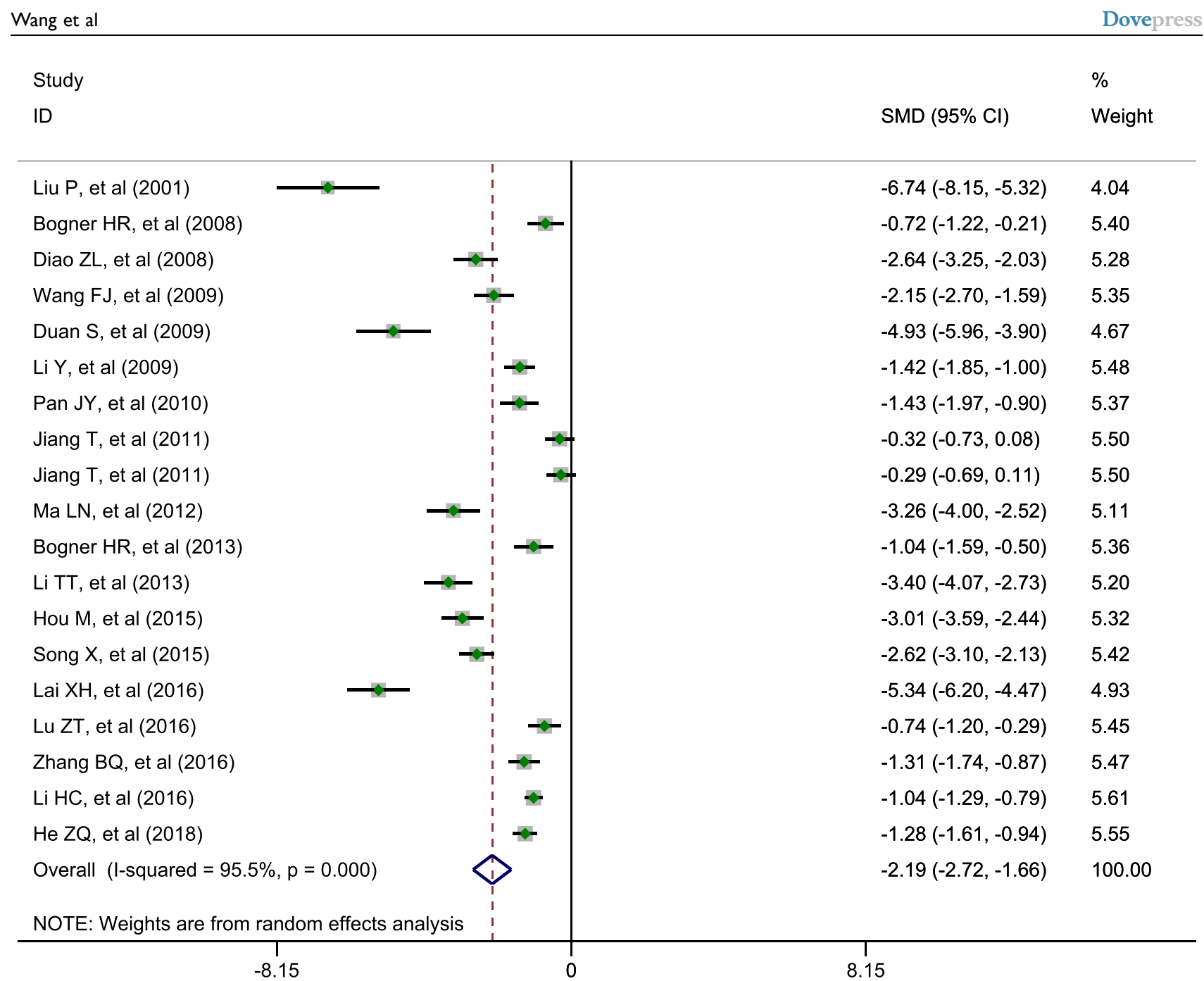

Figure 5 Depression score were estimated from meta-analysis of hypertensive depression patients with combination treatment (intervention group) versus usual antihypertensive treatment (control group).

as opposed to antihypertensive treatment alone. Compared with the common antihypertensive treatment, combination treatment improved SBP by $11.27 \mathrm{mmHg}$ and DBP by $8.21 \mathrm{mmHg}$, and increased antihypertensive treatment efficiency by $42 \%$ in hypertensive patients with depression. To the best of our knowledge, our study is the first to systematically summarize the effects of combination treatment on BP and antihypertensive efficiency in a meta-analysis of RCTs.

Hypertension is a major public health problem worldwide due to its high prevalence and concomitant risks of CVD. ${ }^{45,46}$ The condition commonly co-exists with depression, which is closely associated with high CVD and all-cause morbidity and mortality, significantly more so than hypertension and depression alone. ${ }^{47,48}$ Reduction in BP for hypertensive patients with depression would have a large impact on reducing the burden of disease and might have important public health benefits. Our findings indicate that antihypertensive treatment combined with antidepressants show greater improvement in BP than the common antihypertensive treatment alone.

Combination treatment also significantly increased the antihypertensive efficiency $(R R=1.42)$ in hypertensive patients with depression, which is encouraging. Evidence suggests that depression is significantly associated with poor treatment compliance in patients with hypertension, which is not conducive to the BP control. ${ }^{8}$ In view of the challenges faced by healthcare providers, combination treatment is most likely helpful in improving the control rate of hypertension in patients with comorbid hypertension and depression.

In our analysis, the heterogeneity across studies may have been caused by age, assessment methods of depression, and study publication years. It is worth noting that age is the main source of heterogeneity. Papazacharias et al indicated in 


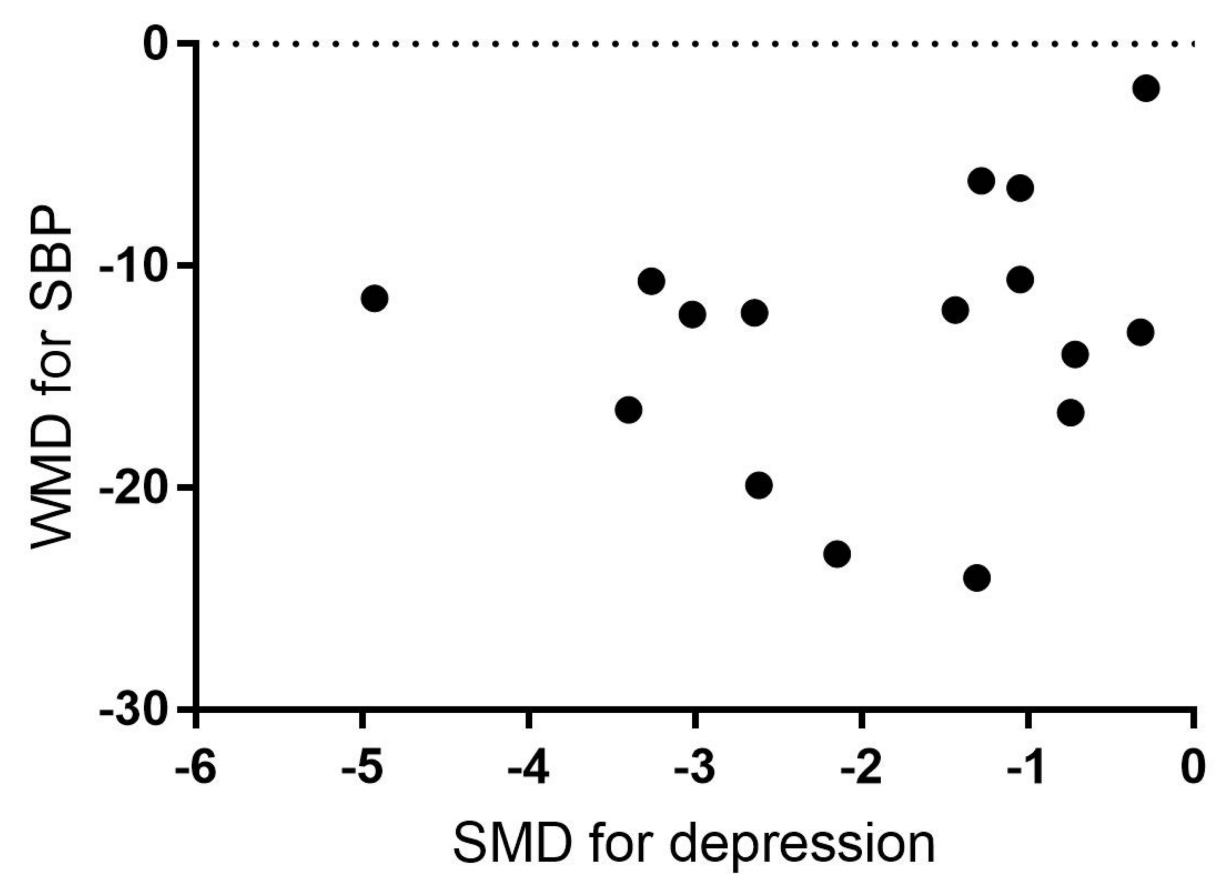

A

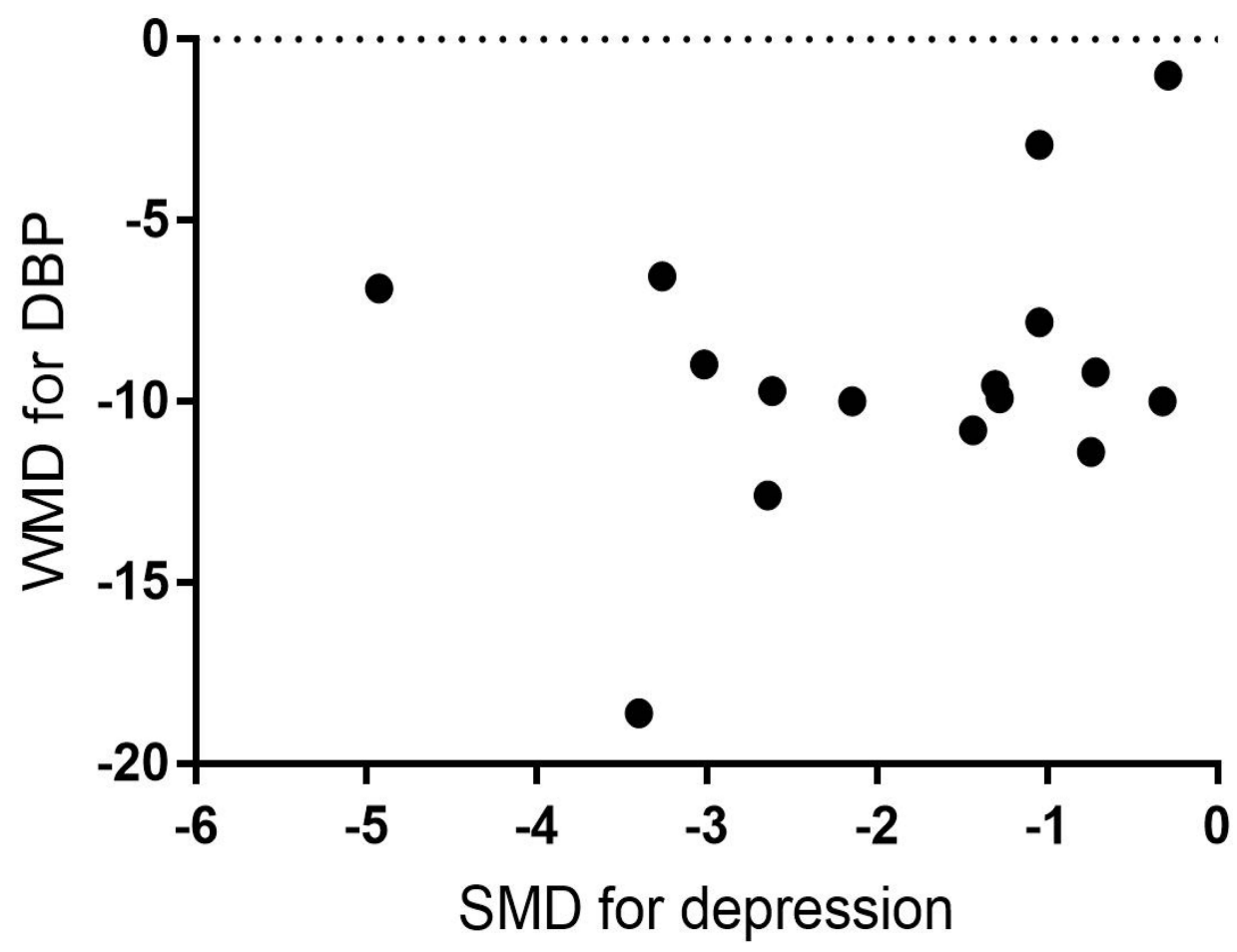

B

Figure 6 Scatter plot displaying the association between the standardized mean difference (SMD) in depression outcomes and the weighted mean difference (WMD) in SBP and BDP values in each study.

Notes: (A) for SBP, (B) for DBP. 


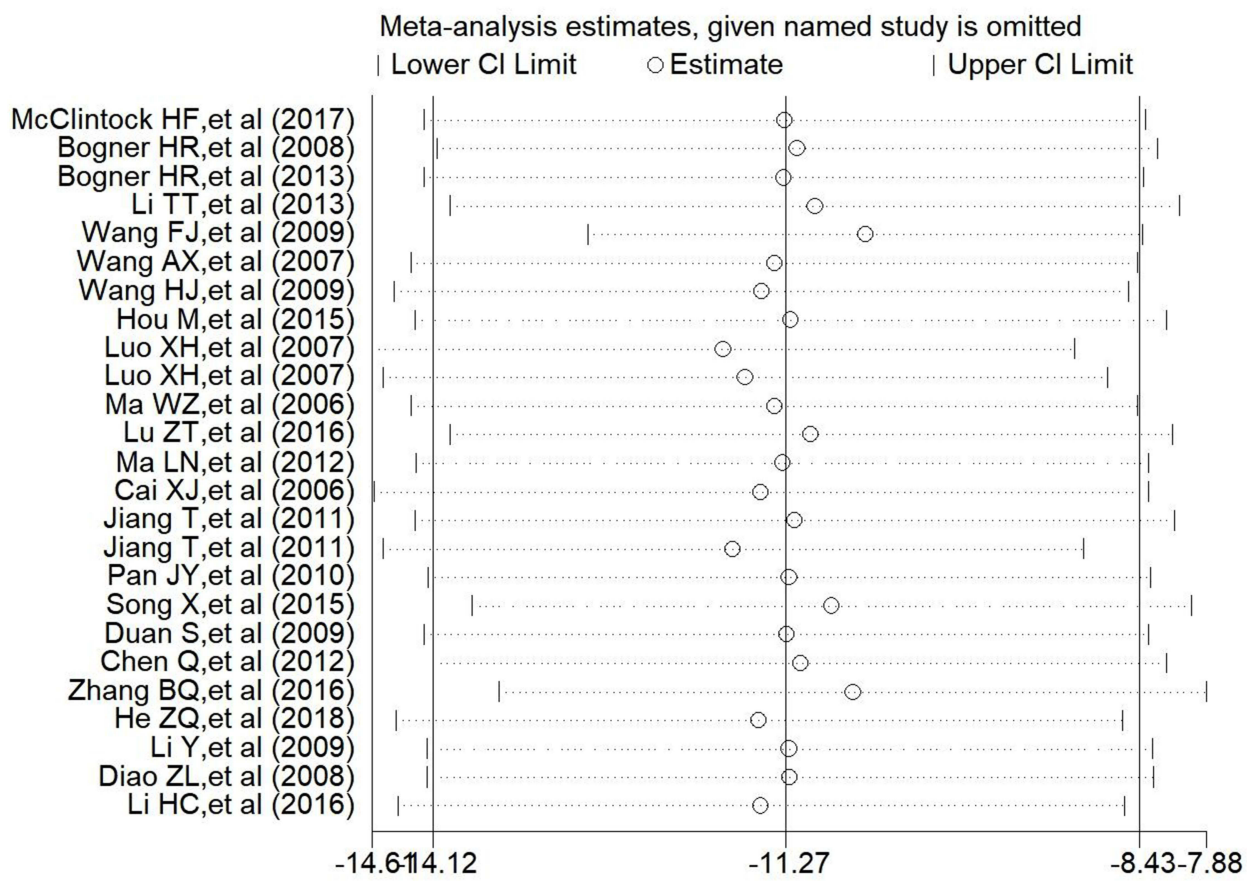

Figure 7 The sensitivity analysis of WMD of SBP.

their study that late-onset depression (ie, the first episode of depression occurs later in life) has a different aetiology than early-onset depression (ie, the first episode of depression occurs earlier in life) ${ }^{49}$ The former is highly correlated to vascular pathology, since late-onset depression presents with more severe cerebrovascular pathology and structural brain abnormalities than age-matched early-onset depression, which is in line with the vascular depression hypothesis proposed by Aizenstein et al. ${ }^{50}$ Consistently, our results in different age groups show that the effects of combination treatment on blood pressure reduction in participants aged $<65$ years were greater than that in patients aged $\geq 65$ years. Consequently, collaborative care of mental health in the elderly should be considered while also using a variety of psychotherapeutic approaches. These may include interpersonal psychotherapy and cognitive problem-solving, both of which may be helpful in managing late-life depression resistant to antidepressant medications. ${ }^{51}$

Although this meta-analysis included 27 RCTs and failed to confirm the association between combination treatment and endpoints such as morbidity and mortality, our findings indicate that combination treatment has a clinically meaningful and statistically significant effects on both SBP and DBP (decreased by $11.27 \mathrm{mmHg}$ and $8.21 \mathrm{mmHg}$, respectively), compared with the common antihypertensive treatment. A systematic review of 147 RCTs with 958,000 participants showed that a decrease in SBP by $10 \mathrm{mmHg}$ or DBP by $5 \mathrm{mmHg}$ reduced approximately $25 \%$ total coronary Heart disease events and 30\% of stroke events, regardless of blood pressure and CVD presence before treatment. ${ }^{52}$ Accordingly, great clinical and socioeconomic benefits could be achieved with the significant BP-lowering effects of combination treatment. However, the treatment duration of the included trials was between 4 and 12 weeks, and despite the significant BP-lowering effects after short-term treatment, long periods of antidepressant use in these patients may present their own set of challenges. ${ }^{53}$ For instance, antidepressant drugs may negatively affect health by disrupting adaptive processes, such as in the immune system. Further studies are needed to investigate the roles of long-term antidepressant and antihypertensive use in reducing CVD and all-cause mortality and maintaining optimal health of comorbid patients.

\section{Limitations}

First, a portion of the included studies had insufficient reported methodology, which attenuates our comments on quality. Second, the assessment tools for depression across eligible studies were not entirely consistent. Although standardized 
Table I Effect of Combined Treatment on Systolic Blood Pressure in Randomized Clinical Trials Among Hypertensive Patients Combined with Depression by Subgroups

\begin{tabular}{|c|c|c|c|c|c|c|}
\hline Subgroup & $\begin{array}{c}\text { Trials, } \\
\text { no. }\end{array}$ & WMD $(95 \% \mathrm{Cl})$ & P-value & $\begin{array}{c}\text { P-value for } \\
\text { heterogeneity }\end{array}$ & $1^{2}$ & $\begin{array}{l}\text { P-value for } \\
\text { difference }\end{array}$ \\
\hline \multicolumn{7}{|l|}{ Country } \\
\hline China & 22 & $-11.21(-14.23,-8.43)$ & $<0.001$ & 0.851 & $0.0 \%$ & 0.877 \\
\hline US & 3 & $-11.89(-16.99,-6.79)$ & $<0.001$ & $<0.001$ & $96.0 \%$ & \\
\hline \multicolumn{7}{|c|}{ Mean age, years } \\
\hline$<65$ & 14 & $-13.83(-17.51,-10.15)$ & $<0.001$ & $<0.001$ & $91.0 \%$ & 0.020 \\
\hline$\geq 65$ & 11 & $-8.20(-11.19,-5.22)$ & $<0.001$ & $<0.001$ & $93.3 \%$ & \\
\hline \multicolumn{7}{|c|}{ Assessment of depression } \\
\hline HAMD & 21 & $-10.52(-12.89,-8.16)$ & $<0.001$ & $<0.001$ & $92.0 \%$ & 0.153 \\
\hline Others & 4 & $-|5.4|(-23.28,-7.54)$ & $<0.001$ & 0.001 & $82.3 \%$ & \\
\hline \multicolumn{7}{|c|}{ Types of antidepressants } \\
\hline TCA & 5 & $-13.99(-20.53,-7.44)$ & $<0.001$ & $<0.001$ & $96.5 \%$ & 0.251 \\
\hline SSRI & 17 & $-10.24(-12.90,-7.58)$ & $<0.001$ & $<0.001$ & $92.3 \%$ & \\
\hline \multicolumn{7}{|c|}{ Year of publication } \\
\hline Before 2010 & 11 & $-9.77(-14.97,-4.58)$ & $<0.001$ & $<0.001$ & $97.2 \%$ & 0.277 \\
\hline After 2010 & 14 & $-12.48(-15.74,-9.23)$ & $<0.001$ & $<0.001$ & $91.8 \%$ & \\
\hline \multicolumn{7}{|l|}{ Sample size } \\
\hline$<100$ & 17 & $-11.52(-15.71,-7.34)$ & $<0.001$ & $<0.001$ & $96.3 \%$ & 0.814 \\
\hline$\geq 100$ & 8 & $-11.27(-14.12,-8.43)$ & $<0.001$ & $<0.001$ & $87.7 \%$ & \\
\hline
\end{tabular}

Abbreviations: WMD, weighted mean difference; HAMD, Hamilton Depression Scale; TCA, tricyclic antidepressants; SSRI, selective serotonin reuptake inhibitor.

Table 2 Effect of Combined Treatment on Diastolic Blood Pressure in Randomized Clinical Trials Among Hypertensive Patients Combined with Depression by Subgroups

\begin{tabular}{|c|c|c|c|c|c|c|}
\hline Subgroup & $\begin{array}{c}\text { Trials, } \\
\text { no. }\end{array}$ & WMD $(95 \% \mathrm{Cl})$ & P-value & $\begin{array}{c}\text { P-value for } \\
\text { heterogeneity }\end{array}$ & $1^{2}$ & $\begin{array}{l}\text { P-value for } \\
\text { difference }\end{array}$ \\
\hline \multicolumn{7}{|l|}{ Country } \\
\hline China & 22 & $-8.24(-10.94,-5.55)$ & $<0.001$ & $<0.001$ & 97.3 & 0.933 \\
\hline US & 3 & $-7.98(-11.47,-4.49)$ & $<0.001$ & 0.839 & $0.0 \%$ & \\
\hline \multicolumn{7}{|c|}{ Mean age, years } \\
\hline$<65$ & 14 & $-10.09(-12.73,-7.44)$ & $<0.001$ & $<0.001$ & $92.6 \%$ & 0.007 \\
\hline$\geq 65$ & 11 & $-5.82(-8.06,-3.57)$ & $<0.001$ & $<0.001$ & $90.1 \%$ & \\
\hline \multicolumn{7}{|c|}{ Assessment of depression } \\
\hline HAMD & 21 & $-8.16(-11.21,-5.12)$ & $<0.001$ & $<0.001$ & $97.2 \%$ & 0.826 \\
\hline Others & 4 & $-9.87(-10.75,-8.99)$ & $<0.001$ & 0.670 & $0.0 \%$ & \\
\hline \multicolumn{7}{|c|}{ Types of antidepressants } \\
\hline TCA & 5 & $-10.76(-15.68,-5.84)$ & $<0.001$ & $<0.001$ & $97.4 \%$ & 0.101 \\
\hline SSRI & 17 & $-7.38(-9.49,-5.27)$ & $<0.001$ & $<0.001$ & $91.1 \%$ & \\
\hline \multicolumn{7}{|c|}{ Year of publication } \\
\hline Before 2010 & 11 & $-7.26(-10.27,-4.24)$ & $<0.001$ & $<0.001$ & $95.9 \%$ & 0.313 \\
\hline After 2010 & 14 & $-8.95(-12.64,-5.25)$ & $<0.001$ & $<0.001$ & $95.8 \%$ & \\
\hline \multicolumn{7}{|l|}{ Sample size } \\
\hline$<100$ & 17 & $-8.40(-11.32,-5.49)$ & $<0.001$ & $<0.001$ & $95.3 \%$ & 0.710 \\
\hline$\geq 100$ & 8 & $-7.78(-11.23,-4.33)$ & $<0.001$ & $<0.001$ & $94.1 \%$ & \\
\hline
\end{tabular}

Abbreviations: WMD, weighted mean difference; HAMD, Hamilton Depression Scale; TCA, tricyclic antidepressants; SSRI, selective serotonin reuptake inhibitor. 
Table 3 Effect of Combined Treatment on Systolic Blood Pressure in Randomized Clinical Trials Among Hypertensive Patients Combined with Depression by Meta-Regression

\begin{tabular}{|c|c|c|c|c|}
\hline Covariates & Meta-Regression Coefficient & $95 \% \mathrm{Cl}$ & P-value & Variance Explained (\%) \\
\hline \multicolumn{5}{|l|}{ Univariate analyses } \\
\hline Country (China vs. US) & 0.702 & $-8.56 \mathrm{I}, 9.965$ & 0.877 & $-3.25 \%$ \\
\hline Age group ( $\geq 65$ vs. $<65$ ) & 5.677 & $0.990,10.364$ & 0.020 & $21.16 \%$ \\
\hline Assessment of depression (HAMD vs. Others) & 5.265 & $-2.096,12.626$ & 0.153 & $8.48 \%$ \\
\hline Types of antidepressants (SSRI vs. TCA) & 3.741 & $-2.855,10.338$ & 0.251 & $3.43 \%$ \\
\hline Year of publication (Before 2010 vs. After 2010) & -0.539 & $-1.228,0.149$ & 0.119 & $7.78 \%$ \\
\hline Sample size $(\geq 100$ vs. $<100)$ & 0.643 & $-4.954,6.240$ & 0.814 & $-4.42 \%$ \\
\hline Multivariable analyses & & & & $46.07 \%$ \\
\hline Country (China vs. US) & -11.134 & $-24.562,2.294$ & 0.098 & \\
\hline Age group ( $\geq 65$ vs. $<65$ ) & 5.875 & $-1.296,10.453$ & 0.015 & \\
\hline Assessment of depression (HAMD vs. Others) & 11.394 & $1.667,21.121$ & 0.024 & \\
\hline Types of antidepressants (SSRI vs. TCA) & -6.149 & $-13.554,1.256$ & 0.097 & \\
\hline Year of publication (Before 2010 vs. After 2010) & -0.811 & $-1.431,-0.191$ & 0.013 & \\
\hline Sample size $(\geq 100$ vs. $<100)$ & -0.651 & $-5.743,4.441$ & 0.791 & \\
\hline
\end{tabular}

Abbreviations: HAMD,Hamilton Depression Scale; TCA,tricyclic antidepressants; SSRI,selective serotonin reuptake inhibitor.

Table 4 Effect of Combined Treatment on Diastolic Blood Pressure in Randomized Clinical Trials Among Hypertensive Patients Combined with Depression by Meta-Regression

\begin{tabular}{|c|c|c|c|c|}
\hline Covariates & Meta-Regression Coefficient & $95 \% \mathrm{Cl}$ & P-value & Variance Explained (\%) \\
\hline \multicolumn{5}{|l|}{ Univariate analyses } \\
\hline Country (China vs. US) & -0.2573 & $-6.5537,6.0391$ & 0.933 & $-3.26 \%$ \\
\hline Age group ( $\geq 65$ vs. $<65$ ) & 4.4270 & $-1.3449,7.5092$ & 0.007 & $29.74 \%$ \\
\hline Assessment of depression (HAMD vs. Others) & 0.5593 & $-4.6587,5.7772$ & 0.826 & $-3.50 \%$ \\
\hline Types of antidepressants (SSRI vs. TCA) & 3.5523 & $-0.7520,7.8568$ & 0.101 & $12.38 \%$ \\
\hline Year of publication,continuous & -0.2702 & $-0.7545,0.2141$ & 0.260 & $2.93 \%$ \\
\hline Sample size $(\geq 100$ vs. $<100)$ & 0.6935 & $-3.1124,4.4995$ & 0.710 & $-3.30 \%$ \\
\hline Multivariable analyses & & & & $44.73 \%$ \\
\hline Country (China vs. US) & -0.0904 & $-9.5|39,9.333|$ & 0.984 & \\
\hline Age group ( $\geq 65$ vs. $<65$ ) & 5.3885 & $-2.0489,8.7281$ & 0.003 & \\
\hline Assessment of depression (HAMD vs. Others) & 0.2930 & $-6.6597,7.2402$ & 0.931 & \\
\hline Types of antidepressants (SSRI vs. TCA) & -1.1284 & $-6.8943,4.6375$ & 0.681 & \\
\hline Year of publication, continuous & -0.4879 & $-0.94|7,-0.034|$ & 0.037 & \\
\hline Sample size $(\geq 100$ vs. $<100)$ & -0.3155 & $-4.0365,3.4056$ & 0.860 & \\
\hline
\end{tabular}

Abbreviations: HAMD, Hamilton Depression Scale; TCA, tricyclic antidepressants; SSRI, selective serotonin reuptake inhibitor.

scales of depressive symptoms have been validated and used in population studies, there appears to be significant heterogeneity in the different scale-based results in meta-regression. Third, because a large proportion of short-tomedium duration studies predominantly conducted in China were included, the findings of this review require further research in other countries and studies of longer duration. In particular, the presence of hypertension with comorbid depression has not been recognized in many resource-poor regions or countries.

\section{Conclusions}

The present meta-analysis suggests that combination treatment for hypertensive patients with depression is significantly better at improving blood pressure and has a greater antihypertensive effect than common antihypertensive treatment. Combination treatment is recommended for patients with hypertension and depression. Elderly patients with 


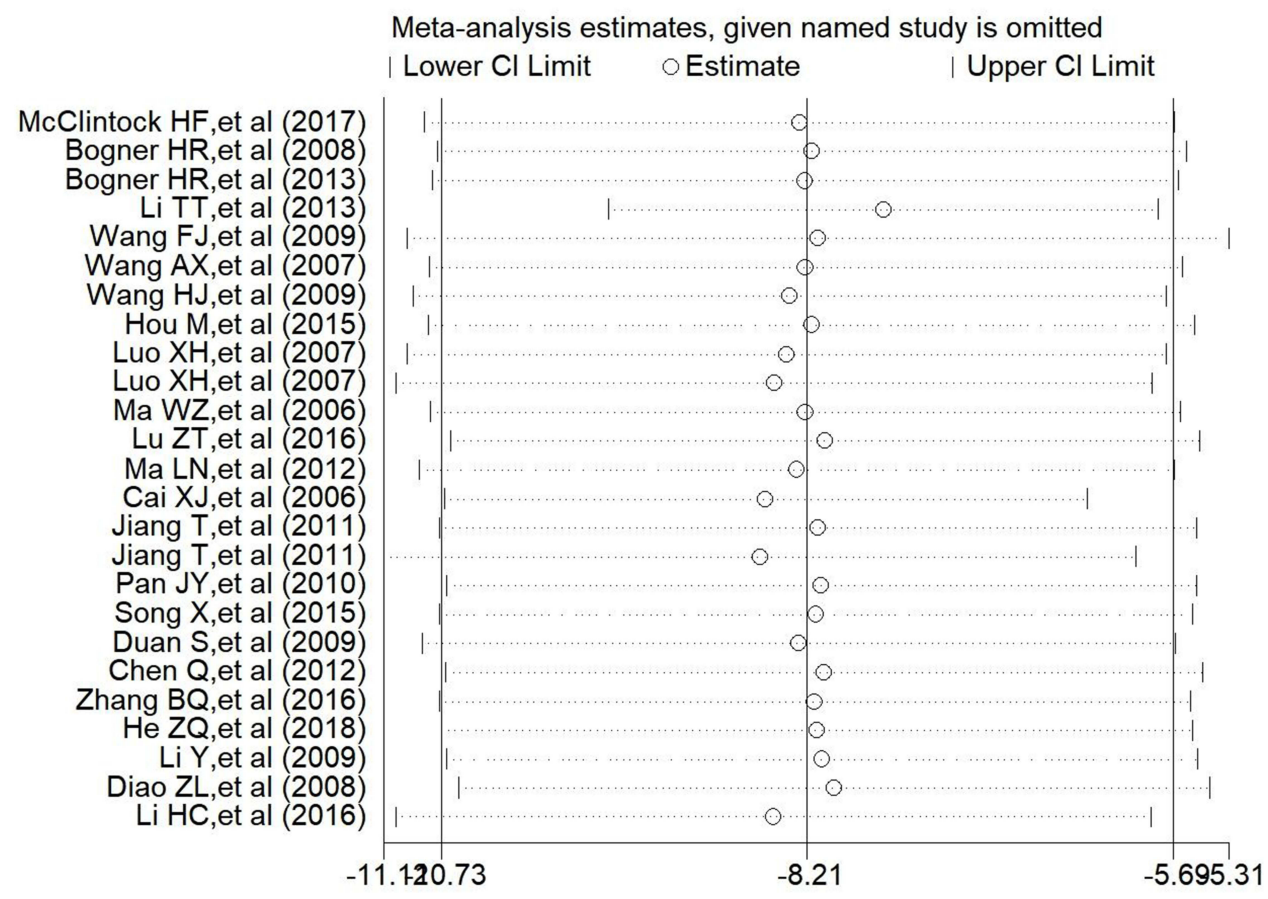

Figure 8 The sensitivity analysis of WMD of DBP.

hypertension and depression may require a more collaborative treatment approach to improve the outcomes of their hypertension. The long-term effects of combination treatments need to be studied further.

\section{Abbreviations}

RCTs, randomized controlled trials; CNKI, China National Knowledge Infrastructure; WMD, weighted mean differences; RR, risk ratios; CI, confidence intervals; SBP, systolic blood pressure; DBP, diastolic blood pressure; CVD, cardiovascular disease; PRISMA, Preferred Reporting Items for Systematic Reviews and Meta-Analyses; SDS, selfreported depression scales; HAMD, Hamilton Depression Scale; TCA, tricyclic antidepressants; SSRI, selective serotonin reuptake inhibitor; SMD, standardized mean differences.

\section{Acknowledgments}

We thank all the authors of the included trials. We would like to thank Editage (www.editage.cn) for English language editing

\section{Author Contributions}

All authors made a significant contribution to the work reported, whether that is in the conception, study design, execution, acquisition of data, analysis and interpretation, or in all these areas; took part in drafting, revising or critically reviewing the article; gave final approval of the version to be published; have agreed on the journal to which the article has been submitted; and agree to be accountable for all aspects of the work.

\section{Funding}

This work was supported by a grant from Basic Public Welfare Research Program of Zhejiang Province (No: LGF20H020009).

\section{Disclosure}

The authors declare that they have no conflicts of interest for this work. 


\section{References}

1. Forouzanfar MH, Liu P, Roth GA, et al. Global burden of hypertension and systolic blood pressure of at least 110 to $115 \mathrm{~mm} \mathrm{Hg}, 1990-2015$. JAMA. 2017;317(2):165-182. doi:10.1001/jama.2016.19043

2. Zhou M, Wang H, Zeng X, et al. Mortality, morbidity, and risk factors in China and its provinces, 1990-2017: a systematic analysis for the Global Burden of Disease Study 2017. Lancet. 2019;394(10204):1145-1158. doi:10.1016/S0140-6736(19)30427-1

3. GBD Causes of Death Collaborators. Global, regional, and national age sex specific mortality for 264 causes of death, 1980-2016: a systematic analysis for the global burden of disease study 2016. Lancet. 2017;390(10100):1151-1210. doi:10.1016/S0140-6736(17)32152-9

4. Mills KT, Stefanescu A, He J. The global epidemiology of hypertension. Nat Rev Nephrol. 2020;16(4):223-237. doi:10.1038/s41581-019-0244-2

5. Chobanian AV, Bakris GL, Black HR, et al. The seventh report of the joint national committee on prevention, detection, evaluation, and treatment of high blood pressure: the JNC 7 report. JAMA. 2003;289(19):2560-2572. doi:10.1001/jama.289.19.2560

6. Xue J, Chen S, Bogner HR, et al. The prevalence of depressive symptoms among older patients with hypertension in rural China. Int J Geriatr Psychiatry. 2017;32(12):1411-1417. doi:10.1002/gps.4628

7. Li Z, Li Y, Chen L, et al. Prevalence of depression in patients with hypertension: a systematic review and meta-analysis. Medicine. 2015;94(31): e1317. doi:10.1097/MD.0000000000001317

8. Demirtürk E, Hacıhasanoğlu Aşılar R. The effect of depression on adherence to antihypertensive medications in elderly individuals with hypertension. J Vasc Nurs. 2018;36(3):129-139. doi:10.1016/j.jvn.2018.06.001

9. Krousel-Wood MA, Frohlich ED. Hypertension and depression: coexisting barriers to medication adherence. J Clin Hypertens. 2010;12 (7):481-486. doi:10.1111/j.1751-7176.2010.00302.x

10. McGirr A, Diaconu G, Berlim MT, et al. Dysregulation of the sympathetic nervous system, hypothalamic-pituitary-adrenal axis and executive function in individuals at risk for suicide. J Psychiatry Neurosci. 2010;35(6):399-408. doi:10.1503/jpn.090121

11. Voinov B, Richie WD, Bailey RK. Depression and chronic diseases: it is time for a synergistic mental health and primary care approach. Prim Care Companion CNS Disord. 2013;15(2):PCC.12r01468. doi:10.4088/PCC.12r01468

12. Bogner HR, de Vries HF. Integration of depression and hypertension treatment: a pilot, randomized controlled trial. Ann Fam Med. 2008;6 (4):295-301. doi:10.1370/afm.843

13. Li Y, Deng WG, Wang SY, et al. Effect of the antidepressant treatment to the blood pressure and quality of life of for hypertension patients with depression. IMHGN. 2012;18(14):2009-2012.

14. Luo XH, Meng WY, Ma Y. Effect of antidepressant treatment on blood pressure of patients with hypertension combined with depression. Shanxi Med. 2007;36(4):439-441.

15. Licht CM, de Geus EJ, Seldenrijk A, et al. Depression is associated with decreased blood pressure, but antidepressant use increases the risk for hypertension. Hypertension. 2009;53(4):631-638. doi:10.1161/HYPERTENSIONAHA.108.126698

16. Higgins JP, Altman DG, Gøtzsche PC, et al. The cochrane collaboration's tool for assessing risk of bias in randomised trials. BMJ. 2011;343:d5928. doi:10.1136/bmj.d5928

17. Higgins JP, Thompson SG, Deeks JJ, et al. Measuring inconsistency in meta-analyses. BMJ. 2003;327(7414):557-560. doi:10.1136/ bmj.327.7414.557

18. Higgins JP, Thompson SG. Quantifying heterogeneity in a meta-analysis. Stat Med. 2002;21(11):1539-1558. doi:10.1002/sim.1186

19. Begg CB, Mazumdar M. Operating characteristics of a rank correlation test for publication bias. Biometrics. 1994;50(4):1088-1101. doi:10.2307/ 2533446

20. Egger M, Davey Smith G, Schneider M, et al. Bias in meta-analysis detected by a simple, graphical test. BMJ. 1997;315(7109):629-634. doi:10.1136/bmj.315.7109.629

21. McClintock HF, Bogner HR. Incorporating patients' social determinants of health into hypertension and depression care: a pilot randomized controlled trial. Community Ment Health J. 2017;53(6):703-710. doi:10.1007/s10597-017-0131-x

22. Bogner HR, de Vries HF, Kaye EM, et al. Pilot trial of a licensed practical nurse intervention for hypertension and depression. Fam Med. 2013;45 (5):323-329.

23. Li TT, Yin CS, Li HQ, et al. A clinical study of the effects of amlodipine combined with flupentixol/melitracen and psychotherapy on essential hypertension in senile patients with mixed anxiety-depressive disorder. Chin J Clin Healthc. 2013;16(06):615-617.

24. Wang FJ, Xian HJ, Shi X. Effect of deanxit on hypertensive patients with depression and anxiety. Chin J Cardiovase Rehabil Med. 2009;18 (06):566-568.

25. Wang AX, Wei S. Effect of Daixin on antihypertensive efficacy and quality of life in patients with hypertension complicated with depression. China Prac Med. 2007;2(28):97-98.

26. Lai XH, Yang PH. Effect of Daixin on antihypertensive efficacy and quality of life in hypertensive patients with depression. Contemporary Med. 2016;22(18):129-131.

27. Wang HJ, Zhang GP, Shao SW. Flupentixol melitracine in the treatment of hypertension with depression. Prev Treatment Cardio-Cerebral-Vasc Dis. 2009;9(05):395-396.

28. Xu TB. Effect of flupentixol melitracine combined with captopril in the treatment of hypertension with depression and anxiety. Contemporary Med. 2016;22(12):143-144.

29. Hou M, Cheng XY, Wang HQ, et al. Clinical study of fluoxetine combined with bebott in the treatment of elderly patients with essential hypertension and depression. Chin J Practl Nerv Dis. 2015;18(23):74-76.

30. Ma WZ, Dou CJ, Zhang RZ. Effect of antidepressant therapy on hypotensive effect of hypertension. Clin Focus. 2006;21(07):477-478.

31. Liu P. Influence of anti-depression therapy on increasing the effect of hypotensor in hypertensive patients. Chin J Cardiovasc Rehabil Med. 2001;10 (03):225-226.

32. Lu ZD, Wang YY, Wang D. The clinical observation about antidepressant treatment on the blood pressure of patients with hypertension combined depression clinical observation. Anhui Med Pharm J. 2016;20(04):764-767.

33. Ma LN, Feng M, Li Y. Investigation of the influence of antidepression therapy on blood pressure and quality of life in elderly patients both with hypertension and depression. Chin J Clinicians. 2012;6(20):6350-6354. 
34. Cai XJ, Bi XP, Zhao Z, et al. The effects of antidepressant treatment on efficacy of antihypertensive therapy in elderly patients with hypertension. Chin J Intem Med. 2006;45(08):639-641.

35. Li WY, Ruan LB. The effects of antidepressant treatment on antihypertensive therapy in elderly patients. J Clin Cardiol. 2011;27(04):275-277.

36. Jiang T. Effect of antidepressant therapy on blood pressure level in patients with hypertension. Hubei J TCM. 2011;33(11):29-30.

37. Pan JY. Effects of paroxetine and psychological intervention on blood pressure level and quality of life in patients with hypertension and depression. China Pharmacist. 2010;13(09):1322-1323.

38. Song X, Yuan Y, Hu QY. Application value of Setraline in essential hypertension patients with depression. China Med Herald. 2015;12 (12):133-136.

39. Duan S, Xiao J, Zhao SP, et al. Effect of antidepressant and psychological intervention on the quality of life and blood pressure in hypertensive patients with depression. J Cent South Univ. 2009;34(04):313-317.

40. Chen Q. Efficacy of enalapril combined with flupentixol melitracine in the treatment of hypertension with depression. Chin J Gerontol. 2012;32 (21):4790-4791.

41. Zhang BQ, Wang M. Observation of the efficacy of escitalopine combined with felodipine in the treatment of hypertension complicated with depression. China Mod Doctor. 2016;54(35):93-96.

42. He ZQ, Chen Y. Analysis of blood pressure changes in elderly patients with hypertension and depression after anti-depressant treatment.China. Mod Med. 2018;25(04):41-43.

43. Diao ZL, Ge QF, Li HT, et al. Effects of antidepressants on blood pressure and inflammation in patients with essential hypertension and depression. Clin Med China. 2008;24(12):1236-1237.

44. Li HC, Li QB, Yang YL, et al. Effect of antidepressant therapy on blood pressure in elderly patients hypertensive patients with depression. Chin $J$ Geriatr Heart Brain Vessel Dis. 2016;18(02):143-148.

45. GBD 2017 Risk Factor Collaborators. Global, regional, and national comparative risk assessment of 84 behavioural, environmental and occupational, and metabolic risks or clusters of risks for 195 countries and territories, 1990-2017: a systematic analysis for the Global Burden of Disease Study 2017. Lancet. 2018;392(10159):1923-1994. doi:10.1016/S0140-6736(18)32225-6

46. GBD 2017 Causes of Death Collaborators. Global, regional, and national age-sex-specific mortality for 282 causes of death in 195 countries and territories, 1980-2017: a systematic analysis for the Global Burden of Disease Study 2017. Lancet. 2018;392(10159):1736-1788. doi:10.1016/ S0140-6736(18)32203-7

47. Graham N, Ward J, Mackay D, et al. Impact of major depression on cardiovascular outcomes for individuals with hypertension: prospective survival analysis in UK Biobank. BMJ Open. 2019;9(9):e024433. doi:10.1136/bmjopen-2018-024433

48. Hamer M, Batty GD, Stamatakis E, et al. The combined influence of hypertension and common mental disorder on all-cause and cardiovascular disease mortality. J Hypertens. 2010;28(12):2401-2406. doi:10.1097/HJH.0b013e32833e9d7c

49. Papazacharias A, Logroscino G, Barulli MR, et al. Late life depression and late onset depression: are the same clinical and pathopsysiological picture? Psychiatr Danub. 2010;22(Suppl 1):S108-S110.

50. Aizenstein HJ, Baskys A, Boldrini M, et al. Vascular depression consensus report-a critical update. BMC Med. 2016;14(1):161. doi:10.1186/ s12916-016-0720-5

51. McGovern AR, Kiosses DN, Raue PJ, et al. Psychotherapies for late-life depression. Psychiatr Ann. 2014;44(3):147-152. doi:10.3928/0048571320140306-07

52. Law MR, Morris JK, Wald NJ. Use of blood pressure lowering drugs in the prevention of cardiovascular disease: meta-analysis of 147 randomised trials in the context of expectations from prospective epidemiological studies. BMJ. 2009;338:b1665. doi:10.1136/bmj.b1665

53. Allan CL, Ebmeier KP. Review of treatment for late-life depression. Adv Psychiatr Treat. 2018;19:302-309. doi:10.1192/apt.bp.112.010835

54. Liberati A, Altman DG, Tetzlaff J, et al. The PRISMA statement for reporting systematic reviews and meta-analyses of studies that evaluate health care interventions: explanation and elaboration. PLoS Med. 2009;6(7):e1000100. doi:10.1371/journal.pmed.1000100

Therapeutics and Clinical Risk Management

Dovepress

\section{Publish your work in this journal}

Therapeutics and Clinical Risk Management is an international, peer-reviewed journal of clinical therapeutics and risk management, focusing on concise rapid reporting of clinical studies in all therapeutic areas, outcomes, safety, and programs for the effective, safe, and sustained use of medicines. This journal is indexed on PubMed Central, CAS, EMBase, Scopus and the Elsevier Bibliographic databases. The manuscript management system is completely online and includes a very quick and fair peer-review system, which is all easy to use. Visit http://www. dovepress.com/testimonials.php to read real quotes from published authors.

Submit your manuscript here: https://www.dovepress.com/therapeutics-and-clinical-risk-management-journal 